\title{
Problem structuring to enable innovation in business/IT projects
}

\section{Tatiana Porté}

Ecole Polytechnique Fédérale de Lausanne School of Computer and Communication Sciences

Station 14, CH-1015 Lausanne, Switzerland

E-mail: tatiana.porte@epfl.ch

\section{Gil Regev}

Ecole Polytechnique Fédérale de Lausanne School of Computer and Communication Sciences Station 14, CH-1015 Lausanne, Switzerland

E-mail: gil.regev@epfl.ch

\section{Alain Wegmann}

Ecole Polytechnique Fédérale de Lausanne School of Computer and Communication Sciences Station 14, CH-1015 Lausanne, Switzerland

E-mail: alain.wegmann@epfl.ch

* Corresponding author

\begin{abstract}
In this paper, we present a project used to teach a problem structuring method in business and IT to STEM students. The project describes an IT consulting case done in a Swiss medical association faced with a problem of change management and digital transformation. We show business analysis techniques of modeling actors' behavior, motivation, and information exchanged between them. We consider appreciative systems of actors and extrapolate the notion of individual norms to community norms. We highlight how accommodation of different viewpoints enables business and IT alignment and innovation. Learning outcomes for students include the ability to model business and IT services, analyze business needs and IT requirements, and structure case information to design a solution in a business/IT project.
\end{abstract}

Keywords: viewpoints, service science, system thinking, appreciative systems, norms. 


\section{Introduction}

This paper addresses the problem of teaching of innovation in business/IT to STEM students. STEM students are not exposed to real-life projects or management education and are therefore not prepared for innovation in companies. They tend to underestimate the importance of understanding the viewpoints of all actors which is a key to understanding the accommodation between them. We propose a problem structuring method in which we analyze the view of the company of interest, of the regulators and the customers. It differs from traditional techniques, e.g. root cause analysis (Solé et al., 2017), which concentrates on problems, and less on who sees the problem and why it is a problem.

This method, called SEAM, is used in a marketing course and a business/IT course in Computer Science Master's program and was used in a course in the EMBA program at EPFL for a module on digital transformation. It is also used in consulting and for innovation coaching. For teaching, we use problem-based learning in which students role-play consultants to understand the context and the structure of the company, analyze problems perceived by stakeholders, enumerate possible solutions, choose the solution that represents a trade-off between value for the stakeholders and the survival of the company, and ultimately design the implementation.

SEAM is being developed since 1997 in the Systemic Modeling Laboratory of EPFL (Regev et al., 2013). SEAM is based on systems thinking and RM-ODP (Wegmann et al., 2007). With it, it is possible to use heuristics on similar problems existing in very different domains (e.g. marketing strategy, organizational strategy, IT strategy).

\section{Case study}

We illustrate the method on a real project of an Association of Family Doctors (AFD) faced with a problem of change management and digital transformation. The AFD case is used as an example of a concrete illustration of our method.

The project explained in the case starts with a project brief - there is a need to develop a database for AFD to manage the internship information used in the coaching of postgraduate medical students who are doing post-graduate training to become family doctors (FD). In our class, we use role-play to teach contextual inquiry (Beyer and Holtzblatt, 1995) as a way to gather information. In this case, we start from a written transcript given in annex. Based on the transcripts and collected information the students are asked to model the service model "as-is" to analyze the problem and design a service model for solution "to-be".

As we stress the importance of viewpoints, we present different models that represent the different viewpoints on the situation. We will model the regulators' viewpoints. Regulators structure their environment and so understanding their point of view allows us to understand the context of the problem. Then we will analyze the view of the customer of the organization which allows us to understand what services are provided to the environment. Then we will consider the view of the president of the organization. These last two views are complementary, the views of the customer describe what the organization provides to its environment, the view of the president describes how the environment helps the company to survive. Regulators and company management have the same motivation 
to maintain the stability of what they are responsible of. Finally, we will construct the updated service model from the point of view of the customer to design a solution to the problem.

All models are results of what people interpret from the reality, the business actors as well as the business analyst. The main principle of SEAM is interpretivism, all people involved in the project need to develop a shared interpretation of what they consider of interest for the situation to address.

\section{Regulator viewpoint - understanding the context}

Heuristic 1. Define the regulators and markets.

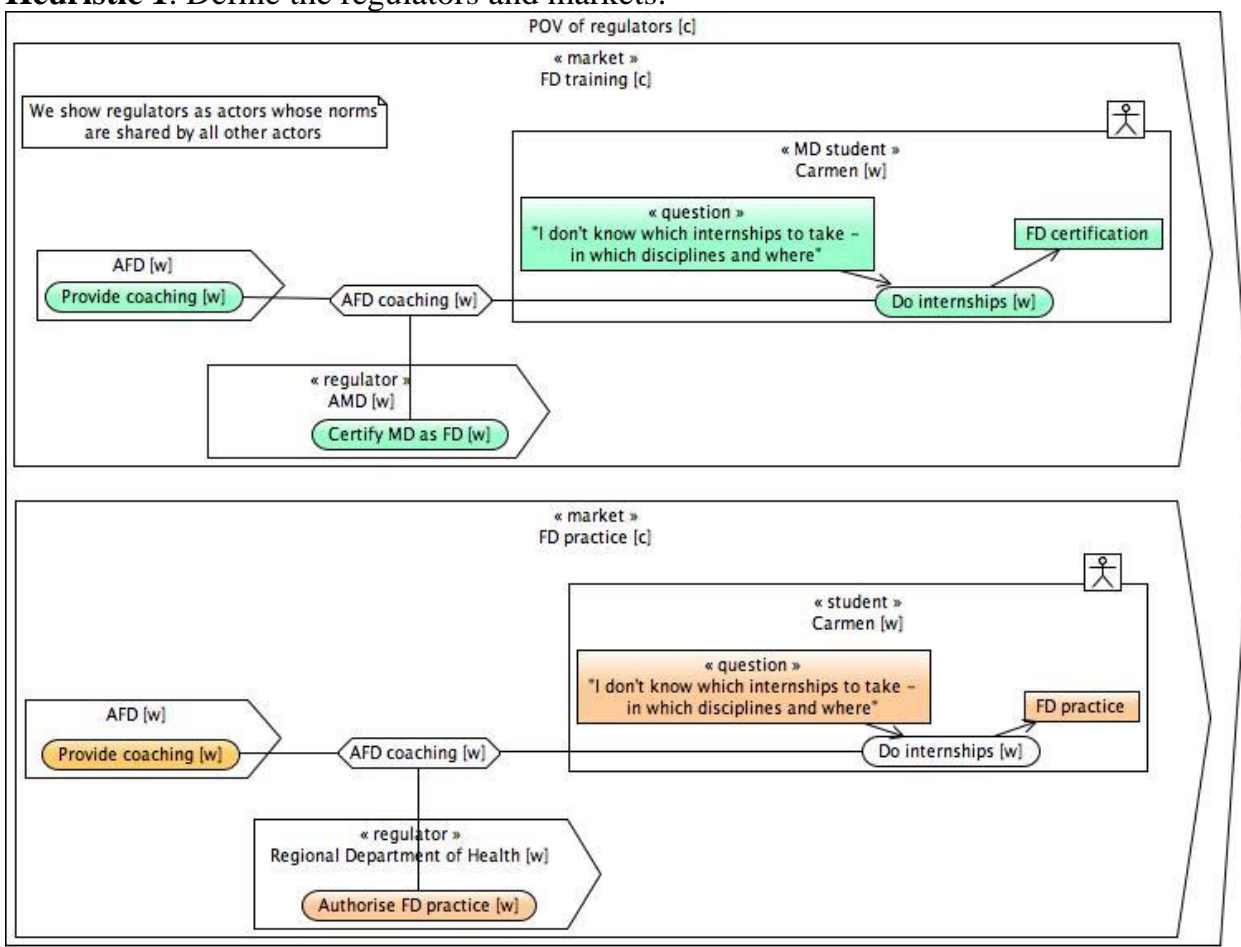

Figure 1 The point of view of regulators

To analyze the behavior of the actors in the market, we do a SEAM service model where we show what actions on macro-level (services) actors do in the market (Fig. 1). In SEAM we use the term "working object" for a system in conceptualization (Regev et al., 2013). To be able to look inside of the working object, we model it as a "composite", denoted as [c] on the model.

When analyzing a group of actors with different viewpoints, we need to model their motivation. In a typical case, there exists a regulator, an actor whose values are shared by other actors to ensure the regulation (Regev and Wegmann, 2011). The regulator can be explicit (e.g. a legislative body) or implicit (e.g. a lobby). In the AFD case, there are two explicit regulators: 
1) the Association of Medical Doctors (AMD) - specifies what is required to be certified as a family doctor. A graduate medical student should do post-graduate training which includes a minimum of 6 years of internships in hospitals. The AMD specifies the minimum set of disciplines that should be practiced there. A federal certificate then allows one to open a practice as an independent practitioner. AMD's motivation is to guarantee FD's competencies.

2) Regional Department of Health - maintain an adequate number of FDs in a region, it authorizes new family doctors to open practice in the region and provides funding to the AFD for medical students who became family doctors after coaching.

We consider the viewpoint of regulators as two "markets" - "FD training" and "Regional practice". The "FD training" market includes all actors relevant to the training of family doctors (universities, hospitals, student housing, medical students, etc.). The "Regional practice" market contains all actors relevant in providing and benefiting from health services (doctors, nurses, hospitals, patients, etc).

The list of markets is a design choice and does not have to be exhaustive and can be amended in the process of analysis. We can argue that each market develops its own set of norms with or without an explicit regulator. For each market we can observe a set of domain terms used by the actors.

\section{Customer viewpoint - understanding what is provided to the environment}

Heuristic 2. Model all actors perceived by the customer.

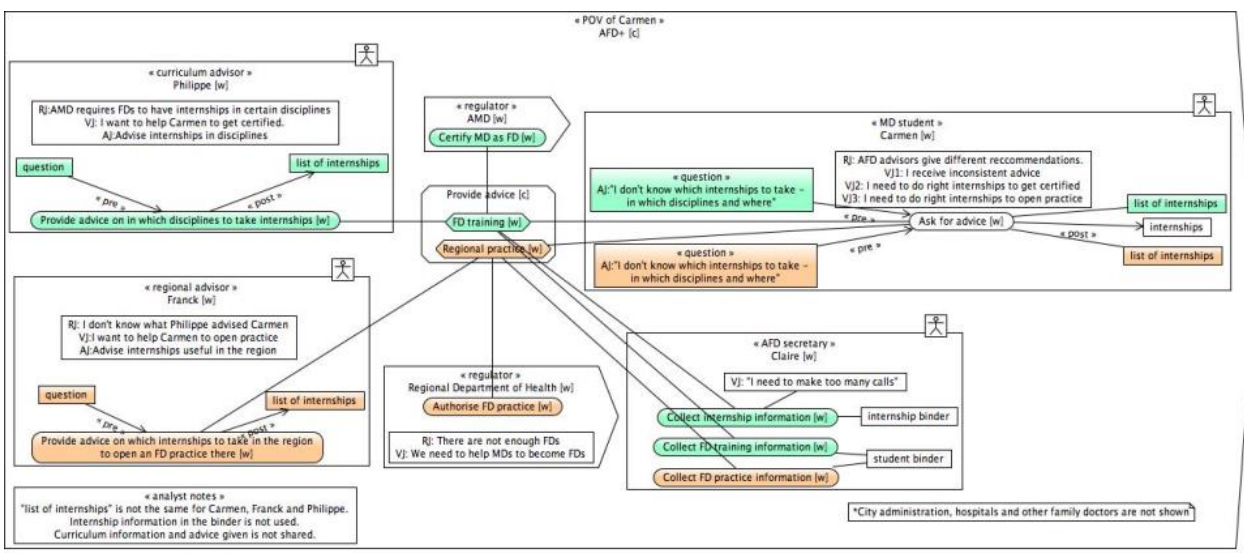

Figure 2 Service model "as-is" from the point of view of a postgrad medical student

In the service model from the customer point of view "as-is" (Fig.1) we model all actors that interact (regardless of the organization in which they belong). We show what services they perform and what information they exchange in the process. In the case, the direct customer of the AFD is personified in Carmen, a graduated medical student whose goal is to get certified as FD and open practice in her home region. It is ideal to base the model on a real person that can be observed. We claim that the direct observation of a customer brings more insight than working with an abstract persona.

Heuristic 3. Ignore organizational boundaries for analysis. 
We do not concentrate on the organizational boundaries of the companies during business analysis. At the same time, for the company of interest (typically the project sponsor) we can consider the organizational view of the legal entity with related constraints in management viewpoint.

\section{Heuristic 4. Model motivation of relevant actors}

The motivation modeling in SEAM is based on Vickers's appreciative systems (Regev et al., 2011). For practical usage, we suggest scoping modeling of reality (RJ), value (VJ), and action judgments (AJ) of all actors to only relevant ones, typically only the customer and the customer of the customer. We show relevant judgments on the service model. For relevant actors we consider the gaps between the reality the actors perceive and their values and norms. The resulting value judgments describe the problems faced by different actors.

Heuristic 5. Model exchanged information

At this level, we model companies as composite working objects and value networks, and people as working object as "whole". We can note which interpretations are shared between actors and which are not. We use the model element "working object" to represent what other people call "system". We believe that we can develop a shared interpretation between the actors of a project only by showing a model. The word "system" is not a model element, it is a way to conceptualize reality and it is extremely observer-dependent and it is always based on tacit knowledge (Lakoff and Johnson, 1980). When considering actors with different points of views it is extremely important to note what properties of the model are interpreted by the actors differently.

Heuristic 6. Add results of analysis as analyst notes

On the service model "as-is" we can observe how the AFD advisors are providing regional and curriculum advice to Carmen, how the AFD secretary collects information about internships and student status. From inquiry it is already known that internship binder is not useful for students (service model shown in annex, Fig.B.1), but modeling "as-is" helps uncover other discrepancies. An analyst, as an external observer, can have a different interpretation of the universe of discourse than other actors which should be captured for analysis. Analyst notes can be of two kinds:

- $\quad$ scoping notes (what is shown and what is not shown for the purpose of the model)

- $\quad$ analysis notes (if there is a discrepancy between the analyst observations and reality judgments of actors as observed by the analyst).

Heuristic 7. The main problem is the problem of the customer and its customer.

In the case, the analyst notes that Carmen is asking what internships she needs to take to fulfill disciplines requirement for certification and, at the same time, what internships can help her open practice in the same region later. But advisors receiving the same question give her inconsistent advice because of:

1) not shared interpretation - both of them provide advice in form of list internships to take but, under influence of the regulator's norms, one of them treats internships as disciplines and the other advisor as regional opportunities

2) not sharing data on student curriculum and previously given advice.

This problem cannot be solved just by the development of a database as requested by the project sponsor. 
This paper was presented at The ISPIM Innovation Conference - Innovating in Times of Crisis, 7-10 June 2020.

Event Proceedings: LUT Scientific and Expertise Publications: ISBN 978-952-335-466-1

Management view - understanding how the environment helps the company to survive

Heuristic 8. Model the metabolic view of the company

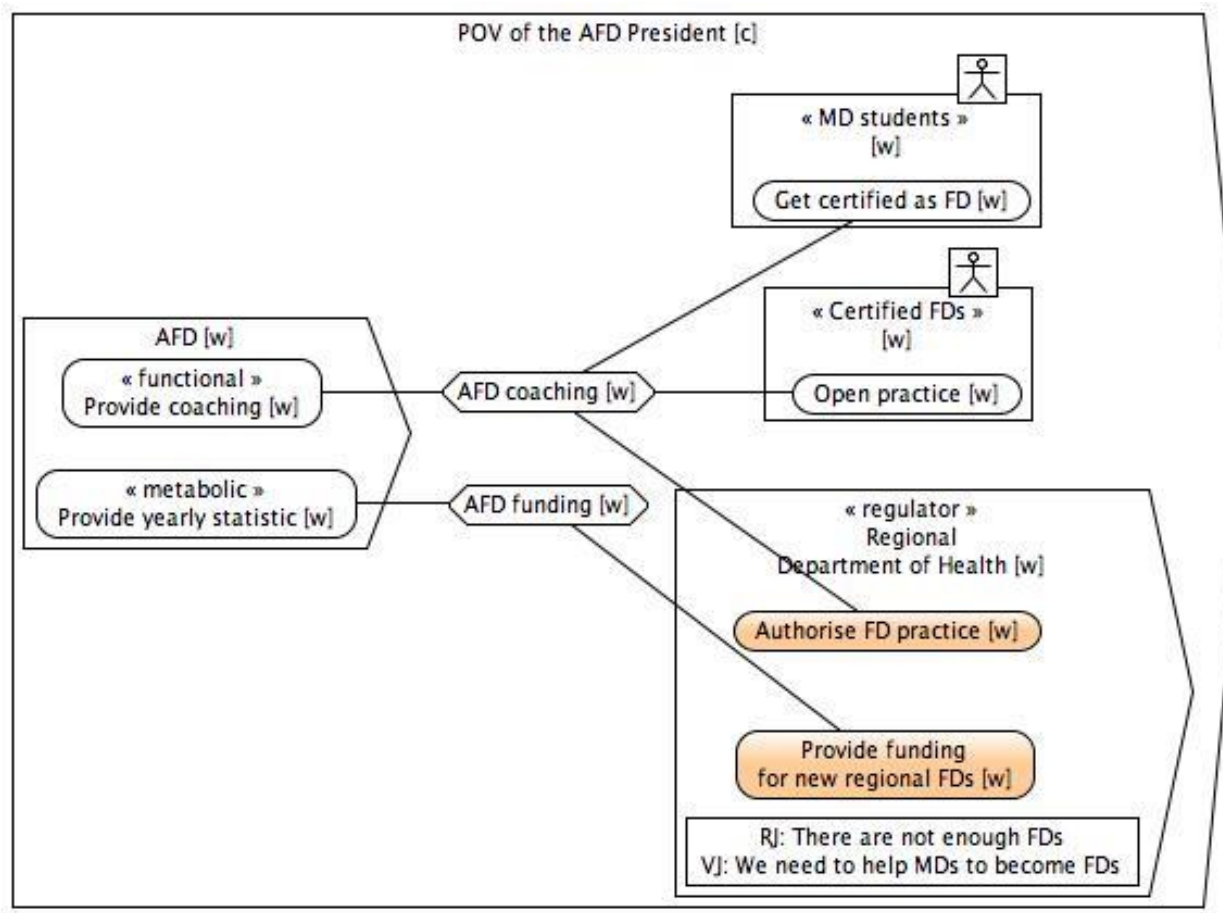

Figure 3 Service model from the point of view of the customer of the customer

When we consider the viewpoint of the customer, we are modeling a functional service that the company is providing. But according to homeostasis principles (Regev et al., 2012), the company needs to ensure its continuing survival. We argue that finding the actor who provides the means for the continuing survival of the company. In the case it is especially evident since the functional service of AFD - coaching of students - is free. The customer of the customer of the AFD is the Regional Health Department (Fig.2) which provides funding and thus ensures the AFD's survival. The funding is dependant only on the conversion rate in the second market, therefore solutions involving ceasing regional advice are counter-productive. At the same time, reducing advice in the first market leads to a reduced number of certified FDs which can open practice, therefore removing curriculum advice to avoid confusion is also impossible.

\section{Bringing viewpoints together - how to better serve the environment to get the means for survival}

Heuristic 9. Improve the service provided to the environment while ensuring that the environment values the service 
We believe that the selection of a solution is indistinguishable from the problem definition. In this case we have defined the problem as the ambiguity of terms and shared information between actors, therefore the designed solution restructures service offering to remove the ambiguity and improve information management.

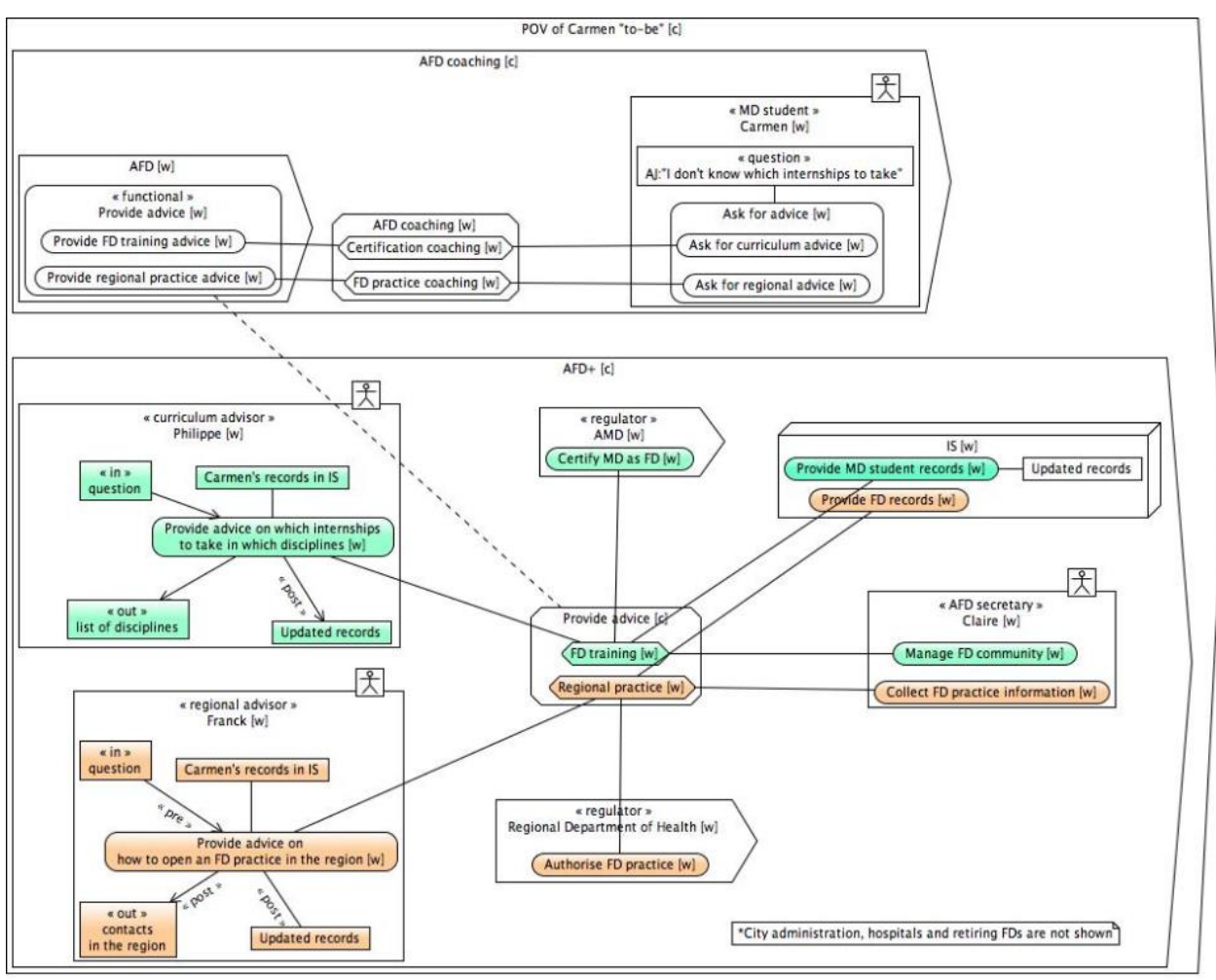

Figure 4 Service model "to-be" from the point of view of a postgrad medical student

In this case we have identified the ambiguity of terms and information exchanged between actors. The designed functional service "to-be" (Fig.3) provides the following changes:

- tracking of internships is replaced with tracking of coaching. It is counter-intuitive to the original project brief but was validated with stakeholders.

- regional advisors now provide networking contacts in the region instead of quickly expiring internships

- the secretary manages the community of family doctors instead of updating binders with internships and student information

- $\quad$ the information system provides secure access to shared curriculum and student information to ensure shared interpretation

Once the solution is selected, we do the behavior model "to-be" where we describe the service offering and service implementation. After the solution is selected and the behavior of actors "to-be" is defined, we do an information model "to-be" as a viewpoint of IT of the company of interest. 
As a side note, in a typical case, the generic solution boils down to correctly selecting the service boundary. We postulate that the boundary of responsibility denotes the area where the actors inside of it can "guarantee" the solution. The selected boundary should not only address the function of the company of interest but also ensure the survival of it through metabolic service. To check the validity of this relationship, we can do a reverse model with the company of interest as the customer of those who are providing the means for its survival, as shown previously in Fig.3.

\section{Applicability discussion}

Problem structuring, analysis, and solution design for business/IT project using the method means constructing a set of service models. Those models can be combined in different ways for their purpose - as viewpoints of actors, as many service layers of customer and customer of the customer, as market segments, etc. There is a tradeoff between the number of people modeled and the number of things that can be seen in parallel.

How do we know that the project is complete? All models have relevance and rigor for a purpose and within a scope. In the academic environment we postulate that the students have finished the project when the developed set of models has a sufficient level of relevance and rigor. In an industry environment, e.g. in consulting or business analysis, the analyst needs to make sure that all stakeholders agree on the shared interpretation.

\section{Model validation}

For validation of the service models with stakeholders, we propose the following relevance levels:

- relevant with shared interpretation;

- relevant without shared interpretation;

- irrelevant.

A transcript produced after an interview or a contextual inquiry typically lacks shared interpretation. Validating a service model with stakeholders ensures the correctness of the model. It can also lead to the reconciliation of not-shared interpretation if the analyst brings discrepancies in interpretations of different actors to their attention. The shared service model is a model all stakeholders agree about (Regev et al., 2013). Scoping criterion - we model all entities necessary for the purpose of the model but as few as possible. We need to avoid modeling actors where we are sure of the execution of the service.

\section{Model verification}

To have a shared conceptualization of the outcome of the service and its implementation, we propose the following rigor criteria:

- Actors need to share necessary information within a working object to perform their service.

- The relationship between "composite" and "whole" view of a working object is well-formed (the model has input and output local properties; service-process relationship is defined).

For business analysis purposes the model in "as-is" does not have to be formally verifiable (therefore the "flat" view is allowed) but formally verifiable "to-be" model using declarative semantics can be used to generate specifications for executable software code (Rychkova et al., 2008). 


\section{Conclusion}

In this paper, we have presented an IT consulting case illustrating how to structure information to solve a problem. We present a set of models and heuristics on how to construct them in order to reconciliate and share conceptualization between people. This method can be used by people who teach and consult in business/IT innovation. It provides patterns useful to analyze different viewpoints and selecting a solution based on thus structured information. The originality lies in the explicit representation of viewpoints, and heuristics on how to make a trade-off between them. We consider functional and metabolic services provided to a customer or a customer of the customer to make sure that the designed solution ensures the survival of the company.

\section{References}

Beyer, H.R., Holtzblatt, K., 1995. Apprenticing with the customer. Communications of the ACM 38, 45-52.

Lakoff, G., Johnson, M., 1980. Metaphors we live by. Chicago, IL: University of Chicago.

Regev, G., Bajic-Bizumic, B., Golnam, A., Popescu, G., Tapandjieva, G., Saxena, A.B., Wegmann, A., 2013. A philosophical foundation for business and IT alignment in enterprise architecture with the example of SEAM, in: Proceedings of the Third International Symposium on Business Modeling and Software Design. SCITEPRESSScience and Technology Publications, pp. 131-139.

Regev, G., Hayard, O., Wegmann, A., 2012. What we can learn about business modeling from homeostasis, in: International Symposium on Business Modeling and Software Design. Springer, pp. 1-15.

Regev, G., Hayard, O., Wegmann, A., 2011. Service systems and value modeling from an appreciative system perspective, in: International Conference on Exploring Services Science. Springer, pp. 146-157.

Regev, G., Wegmann, A., 2011. Revisiting goal-oriented requirements engineering with a regulation view, in: International Symposium on Business Modeling and Software Design. Springer, pp. 56-69.

Rychkova, I., Regev, G., Wegmann, A., 2008. Using declarative specifications in business process design. IJCSA 5, 45-68.

Solé, M., Muntés-Mulero, V., Rana, A.I., Estrada, G., 2017. Survey on models and techniques for root-cause analysis. arXiv preprint arXiv:1701.08546.

Wegmann, A., Regev, G., Rychkova, I., Lê, L.-S., Cruz, J., Julia, P., 2007. Business and IT Alignment with SEAM for Enterprise Architecture. pp. 111-111. 
This paper was presented at The ISPIM Innovation Conference - Innovating in Times of Crisis, 7-10 June 2020.

Event Proceedings: LUT Scientific and Expertise Publications: ISBN 978-952-335-466-1

\section{Annex A}

Interview transcript - Sébastien Chevallaz, AFD President

\section{Sébastien Chevallaz, President, March 5 20XX, Lausanne}

Alain: You asked me to do an on-line database for your association, the Association of Family Doctor. Can you tell me a bit more?

Sébastien: Yes, AFD advises about internships to medical students. We need a database of internships that will be available to all our advisors so that we can improve the advice we give.

Alain: So, the database should contain information about internships?

Sébastien: Yes.

Alain: And internships are 6 months long positions offered by hospitals that medical students take to be certified as medical doctors?

Sébastien: Yes, exactly, only the internships our student take are specified by FMD and should lead them to be certified as family doctors.

Alain: Do all advisors do the same job?

Sébastien: Not really. Curriculum advisors are the first point of contact for a medical student. They follow the student all along his or her studies and make sure they take the internships specified by FMD. Regional advisors help find the recommended internship in the hospitals in their region. They advise students on the internships they should take to be able to open a practice in their region.

Q: So how does it work?

A: The medical student calls a curriculum advisor who meets them regularly and can send them to meet with a regional advisor if needed. The goal is to help complete their postgraduate training and to help understand how to open their practice in their region of interest.

Alain: So, I suppose that the advisors are not all located in the same office? Sébastien: Well, they work out of different places, yes. We have regional advisors in the main city if of each region: for example, Sion for Valais or Lausanne for Vaud. We manage 5 regions: Valais, Fribourg, Genève, Neuchâtel, Jura, Valais and Vaud (all part of the Suisse Romande). The curriculum advisors are in Lausanne (in canton de Vaud), the headquarter of AFD.

Alain: So, they need to all see the same internships through the on-line database? Sébastien: Yes, that's it. That's why I need you.

Alain: And it should be on-line so that the advisors can access it from anywhere they are? Sébastien: Yes.

Alain: What do they use now?

Sébastien: They each have their stuff. Excel, paper, email, whatever. 
Interview transcript - Claire Simmens, AFD Secretary

\section{Claire, secretary, March 12 20XX, Lausanne}

Alain: Hello, I am Alain. I was sent by Sébastien to better understand your work with AFD and the internships.

Claire: Hello. I'm Claire. Pleased to meet you.

Alain: Pleased to meet you. I was wondering whether you could tell me more about the way you manage internships.

Claire: Sure. It's very complicated. I try to figure out which internships are available in hospitals. It's difficult.

Alain: Why is it so difficult?

Claire: Because I can't call the hospitals. I have to ask the advisors.

Alain: Why so?

Claire: Because I don't have contact in hospitals. The advisors do. They're doctors.

Alain: So how does it work? You call an advisor, and?

Claire: And I ask them to tell me which internships are available in which hospital in their region.

Alain: Ah, so you're talking to regional advisors?

Claire: Yes. Well, they're all regional advisors, as you call them.

Alain: So they give you this information?

Claire: Well, not easily. I guess even for them it's difficult to know which internship is available because it changes all the time. A student takes the last internship in a pediatry and suddenly they're noT available.

Alain: So what do you do?

Claire: I do my best. I write down whatever information they give me. Available, not available, no information.

Alain: And where do you write it?

Claire: In my internship binder.

Alain: Can you show it to me?

Claire: Sure. It's there, on the shelf. You can pick it up for me?

Alain: Yup, here it is. Ah, I see you a table with hospitals, internships, status etc. Can I take a picture and show it to Sébastien?

Claire: Of course.

Alain: Oh, I see there are two sections here. What's the other one that says Students? Claire: That one is where I put the information about the internships that the students have taken. There's a sheet for each student. 
This paper was presented at The ISPIM Innovation Conference - Innovating in Times of Crisis, 7-10 June 2020.

Event Proceedings: LUT Scientific and Expertise Publications: ISBN 978-952-335-466-1

Alain: Interesting. Where do you get this information from? From the advisors?

Claire: No, I regularly call the students and ask them where they are.

Alain: Nice. Can I take a picture of this one too?

Claire: Yes, but be careful, it has the names of students on it. Here, put this post-it over the name so it doesn't show.

Alain: Thanks a lot. Just one more question. This binder is here in your office. How do the advisors look at it?

Claire: Philippe is here in Lausanne, so he sometimes comes in and looks at it. The others, like Philippe sometimes come here, less often though. And once every while they call me.

Alain: Great. Thanks again. I'll share this with Sébastien if you agree.

Claire: Sure. I was happy to help.

Alain: May-be a last request, would you mind to help me write a typical and concrete scenario on how AFD provide advice to the MD in training? If you can talk of a case of someone you personally know. This scenario will help me for understanding how things are done concretely.

Claire: I know an FD that just set up a practice. Her name is Carmen Barras. She came to see us at the end of her training as a FD. I know her as we come from the same village, called Randogne, located above Sierre, in Valais. It is closed to the Crans-Montana ski resort.

Carmen did discover AFD via our website, 2 years back. She called us and I did set an appointment with Dr. Sébastien Chevallaz, our president, in Lausanne. It was in the conference room next door. I remember it lasted quite a while. They met and Dr.

Chevallaz asked a lot of feedback on how her work was, he then checked that what was done was compliant to the FMD requirements. Last he gave some recommendations for the remaining internships.

Alain: did he provide actual internship info?

Claire: may-be but I doubt. Usually he recommends the disciplines in which the internships should be done. The actual internships are usually recommended by our contact in the canton. In this case: Dr. Franck de Kalbermatten.

Alain: Do you know how this went.

Claire: Yes as she called me afterward. Her meeting was very useful. It did happen in Sion. She told me that Franck helped her to find internships that were very useful for an FD in Randogne.

Alain: Can you explain more?

Claire: In Winter, the FD in Randogne has to care about ski injuries. So she did her internship in traumatology in Sion.

Alain: and what is Carmen doing now:

Claire: I called her recently. She will open a group practice in Randogne with another FD coming from Geneva. Her practice will allow the current FD in Randogne to retire and his patients will be taken care of by these new doctors. 
Alain: Let me recap who is who in this story. We have:

- Claire Barras, the FD in training,

- Phillipe Chevallaz, as curriculum advisor located in Lausanne,

- Franck de Kalbermatten, as regional advisor located in Sion,

- Christian Aymon, the doctor who did retire

- $\quad$ And yourself, Claire located in Lausanne

Is this correct?

Claire: Yes.

Alain: Obviously, what AFD did for Claire was very useful. Do you do an evaluation of your services with the MD in training? Did Claire suggest some improvements?

Claire: now that you mentioned it, yes indeed.

Alain: Great story, can I use if in my models? Do you think Claire would agree? It would allow us to get a much better understanding of how AFS is working.

Claire: I am sure she will agree. I call her and let you know if she has a problem with you using her story. She is really enthusiastic about what AFD did for her. 
This paper was presented at The ISPIM Innovation Conference - Innovating in Times of Crisis, 7-10 June 2020.

Event Proceedings: LUT Scientific and Expertise Publications: ISBN 978-952-335-466-1

\section{Annex B}

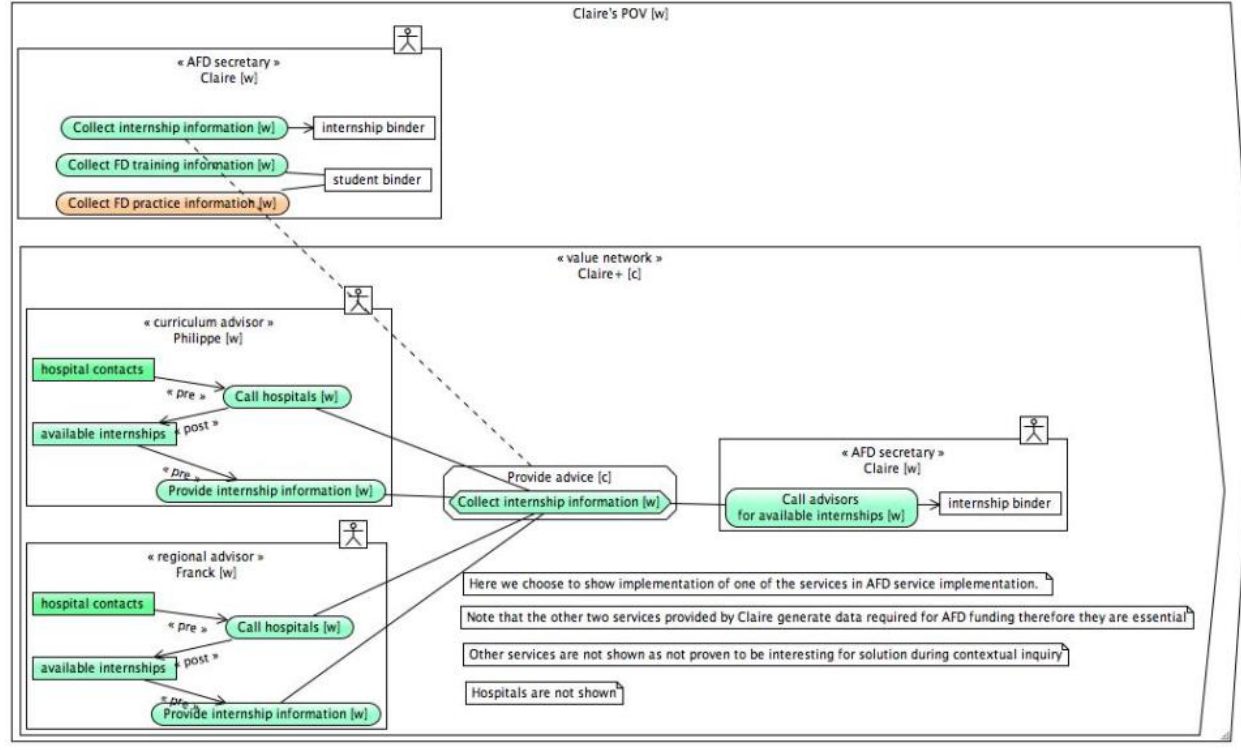

Figure B.1 Point of view of the AFD secretary 